\title{
AOR
}

Selected Papers of \#AolR2021:

The 22nd Annual Conference of the

Association of Internet Researchers

Virtual Event / 13-16 Oct 2021

\section{PERCEIVED INTERCONNECTEDNESS AND THE DEPENDENCE ON AMBIENT CONTEXT ON TWITTER DURING ELECTIONS}

\author{
Ozlem Demirkol Tonnesen \\ University of Southampton
}

“SHUT UP, YOU GOD'S PUNISHMENT TO ALL OF US, JUST SHUT UP” (translated tweet, 2018)

In 2019, as I was analyzing microcelebrity tweets about Turkish presidential elections for my PhD thesis, this tweet drew my attention. It wasn't a part of a thread and it wasn't responding to another tweet, yet it was communicating outrage at something that thousands who retweeted or liked it also felt. I scrolled through the timeline in search of context and after reading a few other tweets that were just as cryptic and emotionally charged, I found it; the president was giving a speech on CNN.

In this paper, I explore the role of ambient context in the encoding and decoding of tweets and the ways such tweets signal perceived affective interconnectedness between users. Here, I build on Abidin's (2015) account on perceived interconnectedness as a performance of intimacy between influencers and followers. I argue that during political events, for Twitter microcelebrities, affect, as in, manifestations of experienced emotions (Papacharissi, 2012), replaces strategies of intimacy in building these bonds. Political events create an environment where intimacy is capitalized to reinforce affective experiences and simultaneously generated through them. Tweets such as the one shared above are analyzed as signifiers of affective interconnectedness that reinforce a 'feeling of community' (Dean, 2010) by setting certain shared offline/online experiences as a prerequisite for engagement and affective bonding.

This research is informed by an interpretive analysis of 97 Turkish Microcelebrity accounts over the three months leading up to the 2018 Turkish presidential and general elections. The interpretive analysis includes open coding of tweets across two columns to interpret the tweet's aims and the communicative means used in the tweet. Thus, the coding process aimed to answer two important questions about the tweets at hand; what the message or purpose is and how it is communicated. Tweets were collected each day in the order they appear on the timeline to replicate a more authentic reading

Suggested Citation (APA): Demirkol Tonnesen, O. (2021, October). Perceived Interconnectedness and the Dependence on Ambient Context on Twitter During Elections. Paper presented at AolR 2021: The 22nd Annual Conference of the Association of Internet Researchers. Virtual Event: AolR. Retrieved from http://spir.aoir.org. 
of the content. One of the biggest challenges I faced in my qualitative analysis was the abundance of context dependent and emotionally charged tweets in the dataset (approx. 20\%). These tweets made sense in a particular moment to a select audience who happen to have the necessary context available to them and lose all meaning when looked at in isolation or after the fact (Sadler, 2017). Indeed, many scholars such as Chadwick (2017) and Papacharissi (2015) have shown that content on social media does not exist in isolation but is often contextualized through other sources of information, and events. Likewise, these tweets encompassed moments as mundane as a TV interview, exemplified in the tweet above, or a news article, which are more difficult to uncover, to bigger moments such as rallies and the election day. Thus, to analyse the tweets that rely on the ambient context, I have also tracked the media events, TV programs, protests and rallies during the data collection period to have a more complete understanding of their meaning.

Among many others such as accessibility and authenticity, intimacy is an essential component of the affective labour of microcelebrity (Raun, 2018), however, how this intimacy is produced differ across platforms, contexts and Influencer genres. Abidin's (2015) research on lifestyle influencers in Singapore show that influencers convey intimacy though a flat power dynamic and reciprocal, disclosive and interactive communication with their followers. Whereas on Twitter, insight into the intimacy between celebrities and their followers was mainly reflected on by Marwick and boyd (2011) who analyse Twitter celebrities that have also achieved fame elsewhere. They suggest that celebrity practitioners on Twitter disclose personal information to build intimacy yet still preserve a level of hierarchy and social distance. However, the microcelebrity accounts that I am observing here are ordinary people who are not celebrities outside of Twitter, thus their positioning is different to the celebrity practitioners. Especially, considering that these microcelebrities' fame comes from their narration of everyday life and commentaries on current events, disclosures and a flat power relationship are indeed important parts of their fame which sets them apart from their celebrity counterparts. Dynamics of localised (i.e national Twittersphere) and Twitter native microcelebrity needs more attention but the research on this topic is yet at its infancy.

Here, I introduce dependence on ambient context as a platform-specific tool for reinforcing intimacy and a signifier of the existing familiarity between Twitter microcelebrities and their audience. I argue that ambient contextualisation of sentiment or message is platform-specific as it is afforded mainly by the fast-paced, in-the-moment and ephemeral logic of micro-blogging. My analysis shows that during events (protests, elections etc.) that are shared/experienced nationally, these tweets that allude to a togetherness in occupying the same space at the same time, such as being among the viewers of a TV programme, replace disclosive intimacies in building affective bonds. For the audience, understanding the frustrations and the subtext in these affective expressions imply a level of sameness between the microcelebrity and the follower, a shared, in-group experience. For instance, right after the elections were once again won by the same party, most tweets were raw with emotions that ranged from disbelief to anger and despair such as "'Are you kidding me????", "I want to wake up tomorrow and notice that today was a dream", "I give up!", "I don't believe in a better future anymore" etc. These tweets are products of viewing Twitter as a conversational space, and they 
are imagined to be situated in a timeline of similar tweets or seen by those who share that moment, which provide the necessary ambient context. Such tweets that are often emotionally charged and conversational allude to shared sorrows, experiences and feelings which are essential in the affective bonding of users however ephemeral it may be (Papacharissi, 2015). These types of expressions have so far been documented in the hashtagged datasets during protests in which the ambiance and context is provided by the hashtag (Papacharissi, 2015). In this paper, I also add to this literature by expanding the understanding of affective publics formed through hashtags onto the communicative intimacies between microcelebrities and audiences during political events.

\section{References}

Abidin, C., 2015. Communicative Ontimacies: Influencers and Perceived Interconnectedness - Ada: A Journal of Gender, New Media, and Technology. [online] Ada: A Journal of Gender, New Media, and Technology. Available at: <http://adanewmedia.org/2015/11/issue8-abidin/>

Chadwick, A., 2017. The hybrid media system: Politics and power. Oxford University Press.

Dean, J. (2010). Affective networks. Media Tropes eJournal, 2(2), 19-44.

Marwick, A. and boyd, d., 2011. To See and Be Seen: Celebrity Practice on Twitter. Convergence: The International Journal of Research into New Media Technologies, 17(2).

Papacharissi, Z., 2012. Without you, I'm nothing: Performances of the self on Twitter. International journal of communication, 6, p.18.

Papacharissi, Z., 2015. Affective publics and structures of storytelling: sentiment, events and mediality. Information, Communication \& Society, 19(3), pp.307-324.

Raun, T., 2018. Capitalizing intimacy. Convergence: The International Journal of Research into New Media Technologies, 24(1), pp.99-113.

Sadler, N., 2017. Narrative and interpretation on Twitter: Reading tweets by telling stories. New Media \& Society, 20(9), pp.3266-3282. 